BMC

Ecology

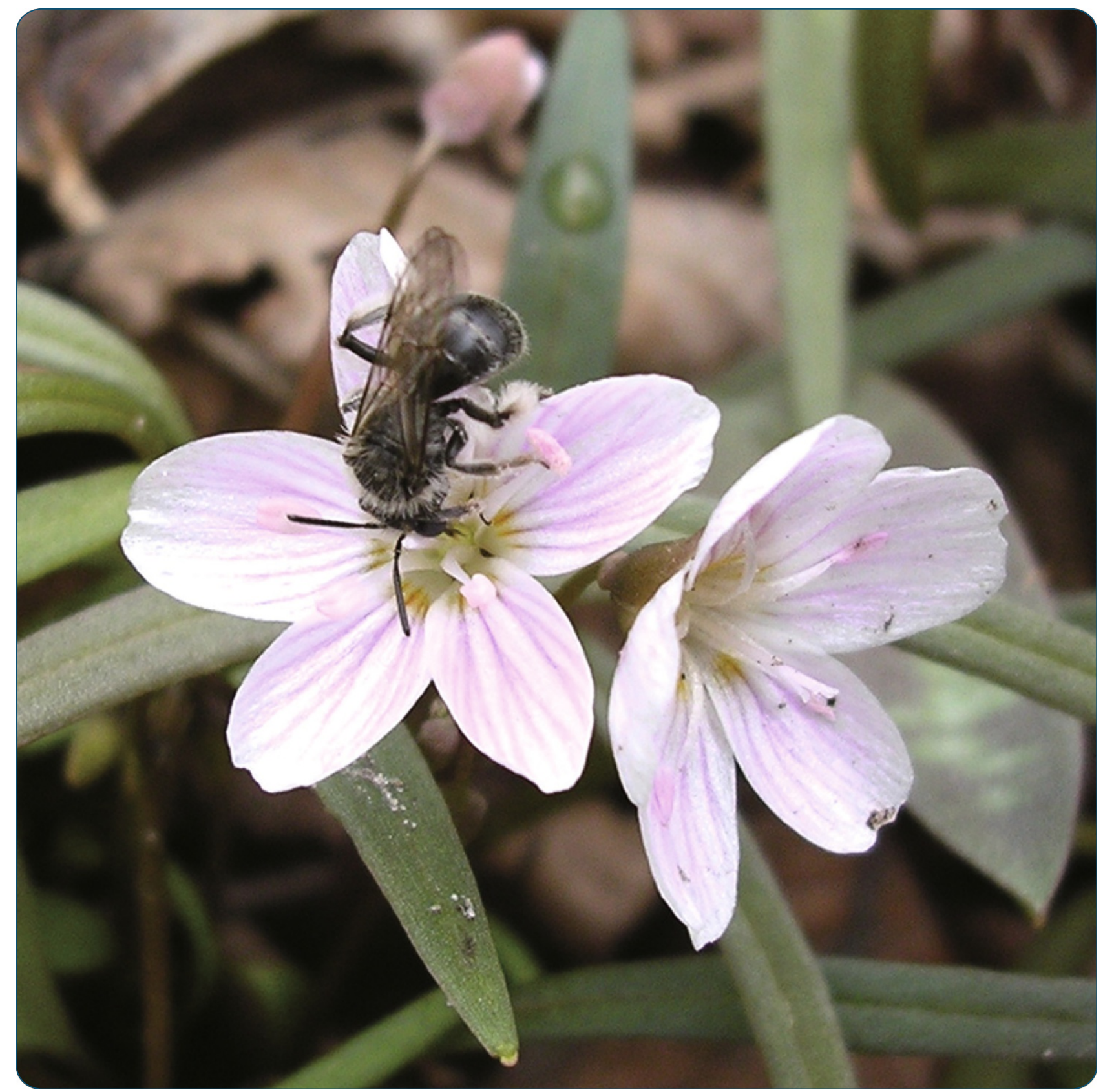

Scale-dependent effects of habitat area on species interaction networks: invasive species alter relationships

Sugiura and Taki

() Biomed Central 


\title{
Scale-dependent effects of habitat area on species interaction networks: invasive species alter relationships
}

\author{
Shinji Sugiura* and Hisatomo Taki
}

\begin{abstract}
Background: The positive relationship between habitat area and species number is considered a fundamental rule in ecology. This relationship predicts that the link number of species interactions increases with habitat area, and structure is related to habitat area. Biological invasions can affect species interactions and area relationships. However, how these relationships change at different spatial scales has remained unexplored. We analysed understory plant-pollinator networks in seven temperate forest sites at 20 spatial scales (radius 120-2020 m) to clarify scale-associated relationships between forest area and plant-pollinator networks.
\end{abstract}

Results: The pooled data described interactions between 18 plant (including an exotic) and 89 pollinator (including an exotic) species. The total number of species and the number of interaction links between plant and pollinator species were negatively correlated with forest area, with the highest correlation coefficient at radii of 1520 and $1620 \mathrm{~m}$, respectively. These results are not concordant with the pattern predicted by species-area relationships. However, when associations with exotic species were excluded, the total number of species and the number of interaction links were positively correlated with forest area (the highest correlation coefficient at a radius of $820 \mathrm{~m}$ ). The network structure, i.e., connectance and nestedness, was also related to forest area (the highest correlation coefficients at radii of 720-820 m), when associations with exotics were excluded. In the study area, the exotic plant species Alliaria petiolata, which has invaded relatively small forest patches surrounded by agricultural fields, may have supported more native pollinator species than initially expected. Therefore, this invasive plant may have altered the original relationships between forest area and plant-pollinator networks.

Conclusions: Our results demonstrate scale-dependent effects of forest area on the size and structure of plant-pollinator networks. We also suggest that a single exotic plant species can impact plant-pollinator networks, even in temperate continental habitats.

Keywords: Alliaria petiolata, Biological invasion, Forest area, Mutualistic networks, Plant-pollinator interactions, Species-area relationships

\section{Background}

The relationship between species number and island area, namely, that species number increases with increasing island area, is a fundamental rule in ecology [1-4]. MacArthur and Wilson [1] hypothesized that this relationship results from a dynamic equilibrium between opposing immigration and extinction rates, which depend on island isolation and size, respectively. Because the

\footnotetext{
*Correspondence: ssugiura@affrc.go.jp

Department of Forest Entomology, Forestry and Forest Products Research Institute (FFPRI), 1 Matsunosato, Tsukuba, Ibaraki 305-8687, Japan
}

same trend occurs in continental environments [1-3], the theory of island biogeography has been applied to the conservation of continental habitats [5-8].

Species-area relationships suggest that the number of interaction links among species, such as prey-predator and plant-pollinator species, increases with island or habitat area $[9,10]$. However, surprisingly, only a few studies have tested this prediction, including one that examined plant-ant interactions on oceanic islands [9], and another that studied plant-pollinator interactions on continental habitats [11]. Additionally, the network structure of species interactions is empirically known to relate to the total

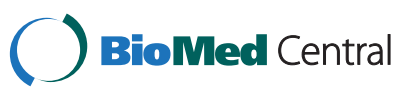


number of species interacting [12-14], which raises the expectation that there may be a close relationship between area and network structure [9]; however, only one study has tested this prediction at the landscape scale [15].

Species-area relationships differ among spatial scales, with the shapes and slopes of the relationships differing among local, regional, and global scales [3,16-18]. In addition, the effects of spatial scale on species-area relationships may depend on taxonomic group; for example, responses to habitat area differ between animals and plants $[3,19]$. Given that networks of species interactions usually involve different taxonomic groups [20,21], different spatial scales may affect the relationships between these networks and habitat area. However, how habitat area influences interaction networks at different spatial scales at the landscape level has remained unexplored.

Biological invasions impact the interactions among native species [22,23], and island communities are more likely to be invaded and affected by exotic species than continental ones [24-26]. However, exotic species may invade continental communities disturbed by human activities $[14,24]$. Therefore, exotic species may impact the original relationship between habitat area and interaction networks even in continental environments.

Here we analysed plant-pollinator networks, both including and excluding exotic species, in temperate continental forests at different spatial scales to clarify scale-variable effects of habitat area on interaction networks. Plant-pollinator interactions provide excellent model systems for investigating the structure of species interactions [12,27-29]. Plant-pollinator interactions have recently been targeted for studying the network structure of plant-animal mutualistic interactions [28-30]. For example, network metrics such as connectance and nestedness are often used to clarify the structure of mutualisitic interaction networks [12-14,31,32]. As network metrics are correlated with the total number of interacting species $[12-14,32,33]$, and the number of species is related to habitat area [1-3], we expect that network structure is also related to habitat area. Reports of such area-related effects on network structure are rare [9], although the mathematical consequences of changing species numbers for network structure have been discussed [31,34].

The main goal of this study was to test the following hypotheses: (1) the total number of species increases with forest area, (2) the network metrics of plant-pollinator interactions are related to the total number of species and forest area, (3) the relationships between forest area and plant-pollinator networks are scale-dependent, and (4) exotic species impact the relationships between forest area and plant-pollinator networks. Although the effects of island and habitat area on interaction networks have recently been reported $[9,11,15]$, the scale-dependencies have never been examined.

\section{Methods}

\section{Study system}

We analysed a data set that was in part used by Taki and Kevan [35] to examine the effects of forest loss on the degree of specialization/generalization for plant and insect communities. Our analyses focused on the effects of forest area on the size and structure of the whole network in terms of scale-dependency and biological invasion. The study was conducted in Norfolk County, Ontario, Canada (Additional file $1 ; 42^{\circ} 37^{\prime}-42^{\circ} 48^{\prime} \mathrm{N}, 80^{\circ} 25^{\prime}-80^{\circ} 39^{\prime} \mathrm{W}$; ca. $200 \mathrm{~m}$ a.s.l.). The study forests were located in southern Ontario's deciduous Carolinian forest zone. The landscape is flat and characterized by distributed fragments of forest within intensively managed agricultural fields of crops such as corn, soybean, and tobacco. The forests were composed of deciduous trees such as oak and maple [36]. Small shrubs and herbs dominated the forest floors. The associations of flower-visiting insects with understory plants that flowered prior to leaf flush of the forest crown trees were examined (Figure 1) by observing the interactions between 18 flowering plants and 89 flower-visiting insect species (Additional file 2 and Additional file 3). Although it is possible that not all of the flower-visitors were legitimate pollinators, we considered them to be pollinators to decipher the general patterns between habitat area and plant-pollinator networks. Garlic mustard Alliaria petiolata and honeybee Apis mellifera, both of which originated in Europe, are exotic species in this region (Additional file 2 and Additional file 3). Both species are widely acknowledged to impact native communities $[37,38]$. However, it is unlikely that $A$. mellifera has become established in the study forests, and the small numbers of individuals captured in this study likely escaped from domesticated colonies. Alliaria petiolata, on the other hand, has become established in these areas, and it invades forest edge and understory.

\section{Study design}

The study was conducted in seven forest sites [35] (Additional file 1), which were selected using a Geographical Information System (GIS) with ArcView (Version 3.3, ESRI, Redlands, CA, USA). Seven geographical points that fell within the forest polygons in the study region were randomly chosen. The criteria for accepting a selected point included a minimum distance of $40 \mathrm{~m}$ from all edges of the forest polygons and a minimum separation distance of $4500 \mathrm{~m}$ from any other chosen geographical points. The geospatial data of forest coverage were produced using aerial photography (1:30000 and 1:50000) obtained from the Ontario Base Map Series in 2003 (Ontario Ministry of Natural Resources, Peterborough, ON, Canada).

Each of the seven selected sites consisted of a hexagonal transect with $20 \mathrm{~m}$ sides with the chosen geographical point marking the centre (Additional file 4). In 

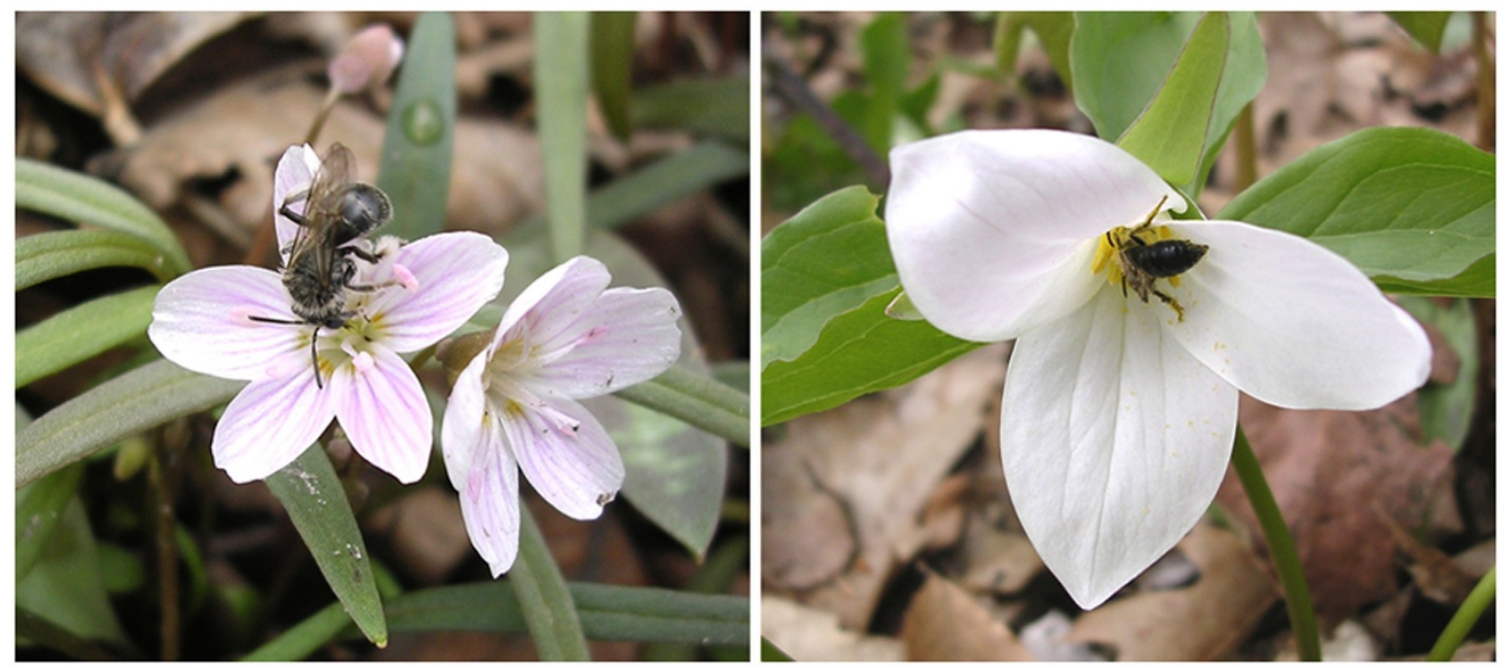

Figure 1 Andrena bee visiting a flower of Claytonia virginica (left) and Trillium grandiflorum (right) in the forest understory.

constructing the hexagonal transects, the direction of the first radial arm of each transect was randomly chosen using a $1.5 \mathrm{~m}$ stick thrown into the air. The axes were marked with bamboo poles and a $120 \mathrm{~m}$ section of rope demarcated the perimeter. Although a better choice for transect shape would be a circle, hexagonal transects were more practical.

A belt transect method [39] was applied to the hexagonal transects. We sampled before canopy closure because most understory plant species bloom during this short season [40-42]. Flower-visiting insects were sampled on sunny days when the temperature was at least $12.8^{\circ} \mathrm{C}$. Sampling started at 11:30 and at 14:30, times at which flower visitations by insects are relatively frequent. Two sites were sampled each day in most cases. Four sampling cycles were conducted to ensure that sampling was carried out twice at 11:30 and twice at 14:30 for each of the seven sites (i.e., each site was sampled on four different days). All samplings were conducted from late April to late May. At each sampling, the same two researchers walked the perimeter of the hexagons five times at a slow pace. One person walked clockwise and the other walked counter-clockwise. Each of these samplings took 80$100 \mathrm{~min}$. All insects visiting the flowers within $2 \mathrm{~m}$ on either side of the perimeter rope were sampled with insect nets and aspirators. The species of the flowering plants visited by each sampled insect were recorded. The species richness and abundance of all flowering plants in bloom at each site were recorded using a quadrate method with $1 \times 1 \mathrm{~m}$ quadrates placed every meter along each side of the perimeter of each hexagon, creating 20 quadrates along the outer perimeter of each side and 19 along the inner row (234 quadrates in total for each recording). The cataloguing and census of plants took place four times for each site, coinciding with the first, second, third, and fourth insect sampling cycle (described above).

To quantify the amount of forest area at different spatial scales, circles of 20 radii from 120 to $2020 \mathrm{~m}$ (100-2000 m from the hexagonal transects) with $100 \mathrm{~m}$ intervals were created using ArcView on maps around each of the hexagonal transects. The scales followed previous studies on foraging ranges and scale-dependent effects in flower-visiting insects such as bees [43-46]. The forest area at each of the scales was estimated by the amount of forest coverage $\left(\mathrm{km}^{2}\right)$ within the circles. The environment surrounding the forests, i.e., intensively managed annual agricultural fields, was not habitat for most of native plant or pollinator species recorded in the study forests. Therefore, we can consider the forest coverage as habitat area for most plant and pollinator species (except for honeybees).

The degree of connectivity among forest patches has been considered one of the most important factors for evaluating the impacts of forest fragmentation on biodiversity [e.g., [47]. In this study area, Taki et al. [46] showed that bee abundance and diversity increased with increasing forest area but not increasing forest edge. This suggests that connectivity has a lesser influence on plant-pollinator networks than the overall forested area in this study region. Therefore, our analyses did not focus on the effects of forest connectivity but rather the effects of forest area on plant-pollinator networks.

\section{Data analysis}

The numbers of species and interaction links were pooled at each forest site for the analyses. To determine the impacts of exotic species on the relationships between forest area and plant-pollinator networks, two 
data sets were analysed; the first included exotic species (i.e., contained all species) and the second excluded associations with exotic plant and pollinator species (i.e., contained only native species).

The numbers of plant species, pollinator species, total species, and occupancy by exotic garlic mustard A. petiolata were analysed in relation to forest area using Pearson's correlation coefficient at each spatial scale. Prior to the analysis, forest area and species numbers were log transformed; occupancy of flowering A. petiolata (proportion of maximum numbers of quadrates out of 234) was square root-arcsine transformed.

To examine how the network metrics were related to the total number of species and forest area, the number of interaction links, connectance, and nestedness were calculated. On the basis of previous studies $[9,11]$, the number of observed interaction links between plant and pollinator species $(I)$ can be predicted to increase with increases in the total number of species and habitat area.

Connectance $(C)$, or the proportion of interactions actually observed amongst all possible interactions, usually represents the degree of redundancy in a system, with consequences for community stability $[12,48]$. It was calculated as follows $[12,31,48]$ :

$$
C=I /(P l \times P o),
$$

where $P l$ and $P o$ are the numbers of plant and pollinator species, respectively. On the basis of previous studies $[12,14,32,33]$, connectance can be predicted to decrease with increases in the total number of species and habitat area.

Nestedness is a pattern composed of asymmetrical interactions between generalists and specialists and symmetrical interactions among generalists. Nestedness is frequently detected within plant-pollinator networks $[13,29,30,49]$, although the concept of nestedness was originally used to analyse patterns of species occurrence and absence on a set of islands or in habitat fragments [50]. Nested networks are characterized by specialist species that tend to interact only with generalists; generalists that all interact with each other, forming a core of interacting species; and the absence of specialists that interact only with other specialists $[28,30]$. We used the software ANINHADO 3.0.3 [51,52] to calculate nestedness (NODF; range 0-100). Relatively large values of $N O D F$ indicate a high degree of nestedness. Two null models (Models I and II provided by ANINHADO 3.0.3) were used to test the degree of nestedness expected from the basic network features. The first null model assumes that each randomly assigned plant and pollinator pair interacts with a constant probability, $C$ (connectance). Therefore, it tests whether the observed NODF is higher than expected for random networks with a similar number of interactions. The second null model assumes that the probability of a plant, $i$, interacting with a pollinator, $j$, depends on the observed number of interactions of both species, such that

$$
C\left(r_{i j}=1\right)=\left(\frac{k_{i}}{P o}+\frac{k_{j}}{P l}\right) \frac{1}{2}
$$

where $k$ is the observed number of interactions for the species, $P l$ is the number of plant species (rows) and $P o$ is the number of pollinator species (columns). Therefore, null model II tests whether the observed NODF is higher than expected for random networks with similar heterogeneities of species interactions. Each community was compared to 1000 replicates generated by each null model. On the basis of the previous study [13], nestedness in mutualistic networks is predicted to increase with increases in the total number of species and habitat area.

The network metrics, link numbers, connectance, and nestedness were also analysed in relation to forest area using Pearson's correlation coefficient at each spatial scale (JMP v. 7.0; SAS Institute, Cary, NC, USA). Before the analysis, $C$ and $N O D F / 100$ were square root-arcsine transformed while link numbers and forest area were log

Table 1 Number of species and network metrics of plant-pollinator interactions in each study forest

\begin{tabular}{llllllll}
\hline Site code & No. plant species & No. pollinator species & No. total species & No. links & No. visitors & Connectance $^{\S}$ & NODF $^{\mathbf{}}$ \\
\hline F1 & $8(8)$ & $17(17)$ & $25(25)$ & $20(20)$ & $34(34)$ & $0.147(0.147)$ & $11.89(11.89)$ \\
\hline F2 & $5(5)$ & $13(13)$ & $18(18)$ & $16(16)$ & $26(26)$ & $0.246(0.246)$ & $28.79(28.79)$ \\
\hline F3 & $12(12)$ & $27(26)$ & $39(38)$ & $34(32)$ & $61(58)$ & $0.105(0.103)$ & $6.83(6.44)$ \\
\hline F4 & $9(8)$ & $40(40)$ & $49(48)$ & $62(40)$ & $135(92)$ & $0.172(0.185)$ & $24.16^{*}(17.64)$ \\
\hline F5 & $3(2)$ & $36(35)$ & $39(37)$ & $37(2)$ & $94(2)$ & $0.343(0.500)$ & $5.53(0)$ \\
\hline F6 & $7(7)$ & $20(20)$ & $27(27)$ & $22(22)$ & $30(30)$ & $0.157(0.157)$ & $4.74(4.74)$ \\
\hline F7 & $4(4)$ & $10(10)$ & $14(14)$ & $11(11)$ & $14(14)$ & $0.275(0.275)$ & $14.38(14.38)$ \\
\hline
\end{tabular}

$\$^{\$}$ The numbers in parentheses indicate the numbers of native plant and native pollinator species, interaction links between native plants and native pollinators, and individuals of native pollinators visiting native plants.

${ }^{£}$ The numbers in parentheses indicate connectance and NODF calculated from the native plant-pollinator interactions (i.e., excluding associations with exotic species).

${ }^{*} P<0.05$ (Model I); other NODF values, $P>0.05$ (Model I and/or II). 


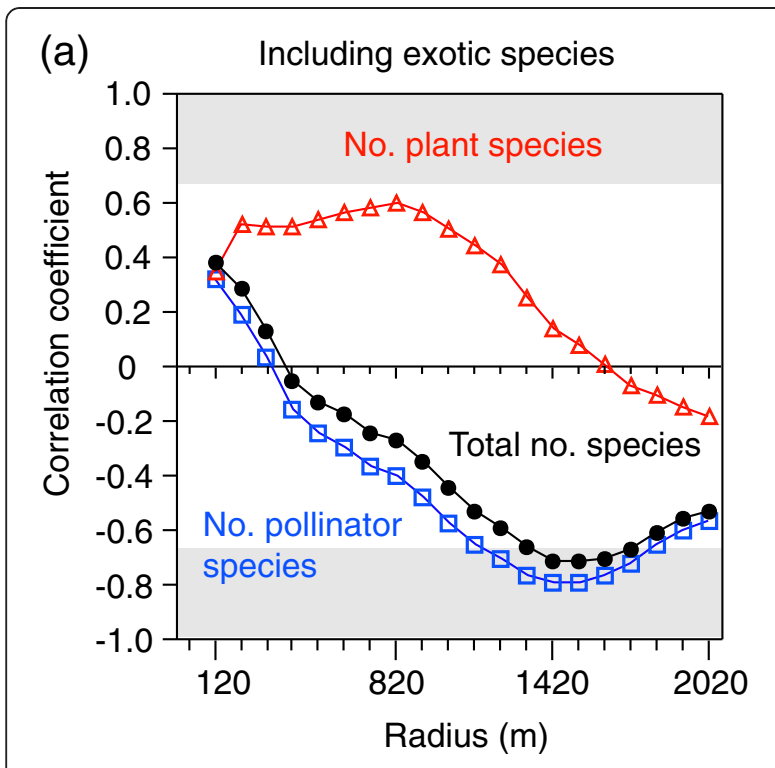

(b) Excluding exotic species and the native species only observed interacting with exotics
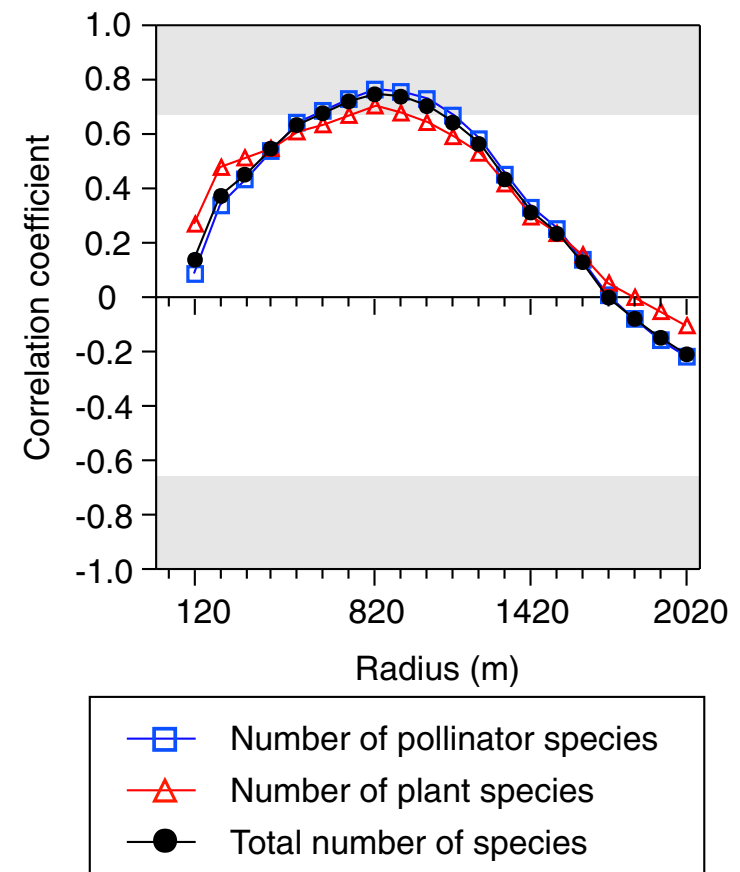

Figure 2 Correlation coefficients between forest area and numbers of species at each radius (range: 120-2020 m) among the study forests: (a) including exotic species, (b) excluding exotic species and the native species only observed interacting with exotics. Correlation coefficients in the shaded grey areas are statistically significant at $p=0.10$ level.

transformed. Linear regression models were used to examine the relationships between the total number of species and network metrics (JMP v. 7.0). We also used linear regression models to investigate the relationships between forest area and network metrics. As the scale for linear regressions, we used the radius at which the highest correlation coefficient was detected.

\section{Results}

Relationships between forest area and species numbers Among study sites, the numbers of plant species, pollinator species, and total species ranged from 3-12, 10-40, and $14-49$, respectively (Table 1 ). The relationships between forest area and numbers of species were dependent on the spatial scale, and differed among plant and pollinator species (Figure 2a). The number of plant species was not related to forest area (at a radius of $820 \mathrm{~m}$ with the highest correlation coefficient; $r^{2}=0.36, \quad F_{1,5}=2.75$, $p=0.158$; Figures $2 \mathrm{a}, 3 \mathrm{a}$ ), while the number of pollinator species and total species were negatively correlated with forest area, with the highest correlation coefficient at radii of 1420 and $1520 \mathrm{~m}$, respectively (Figure 2a, 3c, 3e). These results are not concordant with the patterns predicted by species-area relationships. Occupancy by exotic A. petiolata was negatively correlated with forest area, with the highest correlation coefficient at a radius of $1320 \mathrm{~m}$ (Figure 4). When exotic species, and the native species only observed interacting with exotics, were excluded, the numbers of plant species, pollinator species and total species were positively correlated with forest area, with the highest correlation coefficient at a radius of $820 \mathrm{~m}$ (Figures 2b, 3b, 3d, 3f).

\section{Relationships between species numbers and interaction networks}

The numbers of interaction links between plant and pollinator species ranged from 11-62 among the study sites (Table 1). Of these, the percentage involving exotic species ranged from 0-94.6\% among the study sites (Table 1). The numbers of links were positively correlated with the total number of species (Figure 5a). This pattern did not change when associations with exotic species were excluded from the analysis (Figure $5 \mathrm{~b}$ ). Furthermore, connectance was not related to the total number of species when exotics were included $(C$, including exotics, $0.105-0.343 ; r^{2}=0.10, F_{1,5}=0.53, p=0.50$; Figure $5 \mathrm{c}$ ). However, when associations with exotic species were excluded from the analysis, connectance was negatively correlated with the total number of species $(C$, excluding exotics, 0.103-0.500; Figure 5d). Most of the plantpollinator networks were not nested (NODF, including exotics, 4.74-28.79; excluding exotics, 0-28.79; Table 1). The degree of nestedness was not related to the total number of species regardless of whether the associations with exotic species were excluded from the analysis (including exotics, $r^{2}=0.06, F_{1,5}=0.33, p=0.59$; excluding exotics, $r^{2}=0.31, F_{1,5}=2.21, p=0.20$; Figures $5 \mathrm{e}, 5 \mathrm{f}$ ). 


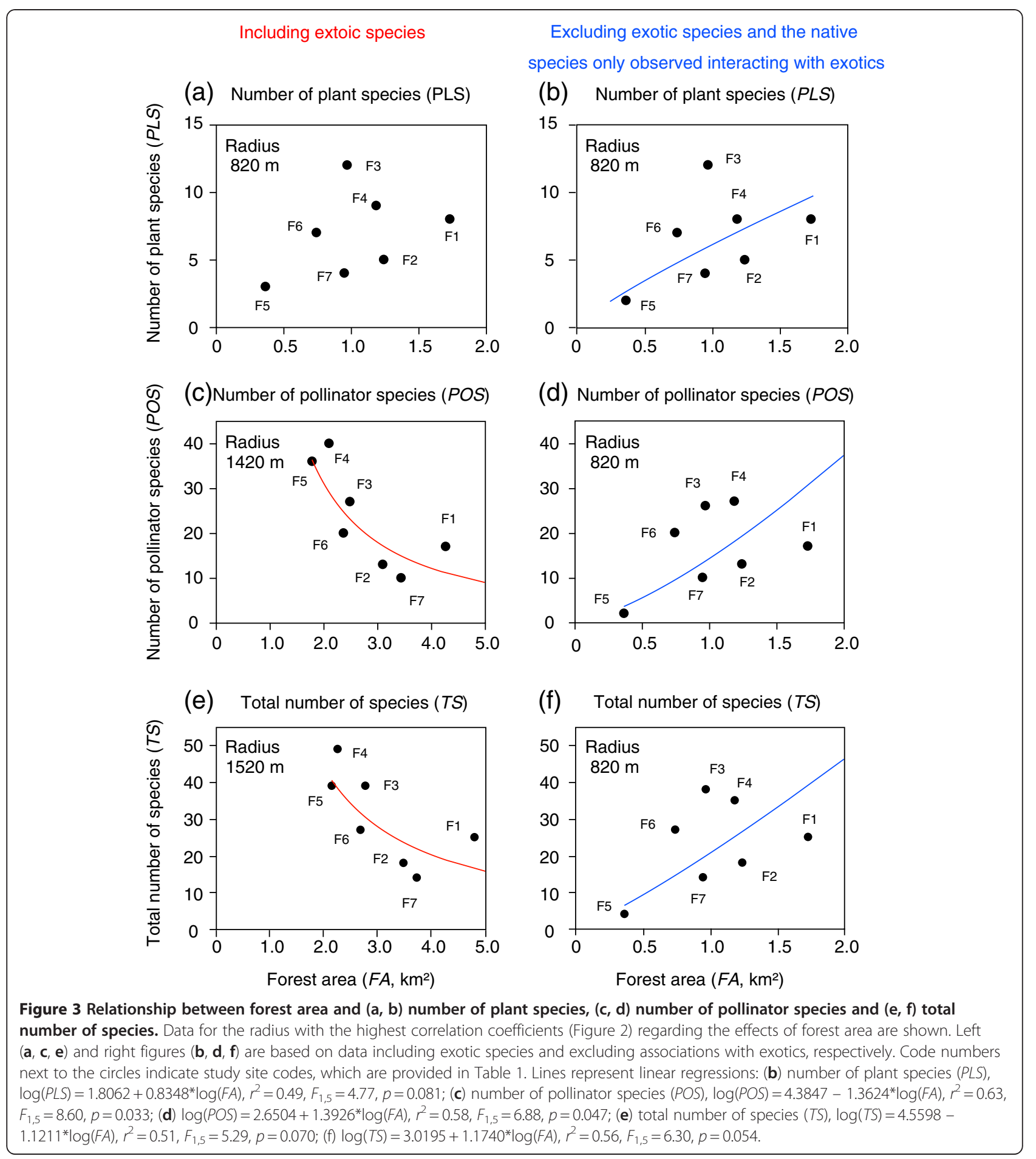

\section{Relationships between forest area and interaction networks}

The numbers of interaction links were negatively correlated with forest area, with the highest correlation coefficient at a radius of $1620 \mathrm{~m}$ (Figures 6a, 7a), which is not concordant with the patterns predicted by species-area relationships. However, when associations with exotic species were excluded from the analysis, the number of interaction links was positively correlated with forest area, with the highest correlation coefficient at a radius of $820 \mathrm{~m}$ (Figures 6b, 7b). Connectance was not related with forest area (at a radius of $820 \mathrm{~m}$ with the highest correlation coefficient; $r^{2}=0.34, F_{1,5}=2.59, \quad p=0.169$; Figures 6a, 7c). However, when associations with exotics 


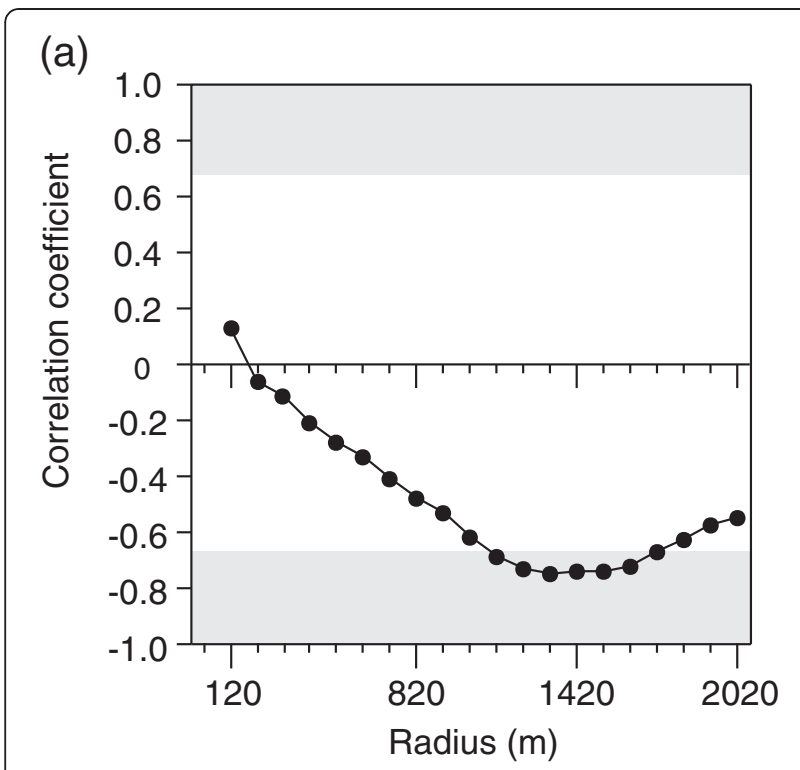

(b)

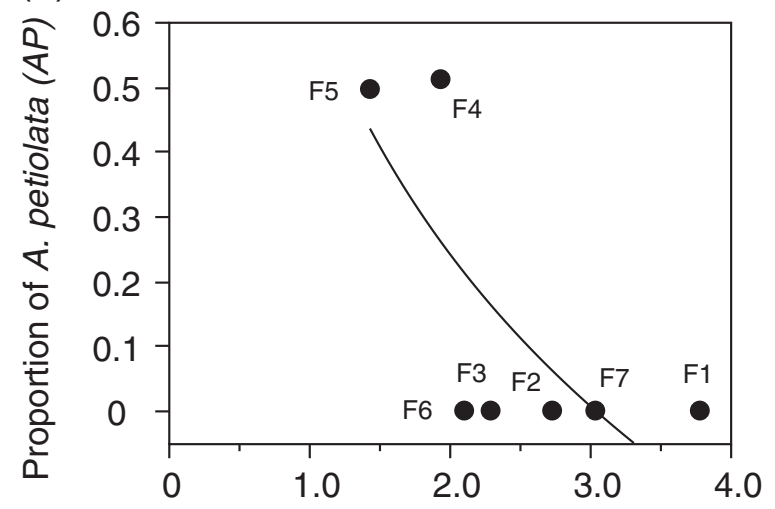

Forest area $\left(F A, \mathrm{~km}^{2}\right)$ at $1320 \mathrm{~m}$ radius

Figure 4 Relationship between forest area and occupancy by the exotic plant Alliaria petiolata. (a) Correlation coefficient between forest area and occupancy by A. petiolata at each radius (range: 120-2020 m) among the study forests. (b) Relationship between forest area at $1320 \mathrm{~m}$ radius and occupancy by $A$. petiolatai. Data for the radius with the highest correlation coefficients regarding the effects of forest area are shown. Code numbers next to the circles indicate study site codes, which are provided in Table 1. Correlation coefficients in the shaded grey areas are statistically significant at $p=0.10$ level. Line represents a linear regression: occupancy by $A$. petiolata (AP, proportion of maximum numbers of quadrates out of 234), $\arcsin \sqrt{A P}=0.6452-0.5800^{*} \mathrm{log}$ $(F A), r^{2}=0.56, F_{1,5}=6.46, p=0.052$.

were excluded from the analysis, connectance was negatively correlated with forest area (highest correlation coefficient at the radius of $820 \mathrm{~m}$; Table 1, Figures 6b, 7d). Nestedness was positively correlated with forest area regardless of whether the associations with exotic species were excluded from the analysis, with the highest correlation coefficients at radii of $520 \mathrm{~m}$ including exotics and 620-720 $\mathrm{m}$ excluding exotics (Table 1, Figures 6, $7 e, 7 f)$.

\section{Discussion}

Some of our results did not support our hypotheses when exotic species were included (Figures 3e, 5c,e, 6a, $7 \mathrm{a}, \mathrm{c})$. However, almost all of the hypotheses were verified when associations with exotic species were excluded from the networks (Figures 3f, 5b,d, 6b, 7b,d,f). In particular, we determined that the relationship between forest area and plant-pollinator network depended on spatial scale (Figures 2, 6). To the best of our knowledge, this is the first study to demonstrate scale-dependent effects of habitat area and exotic species on interaction networks.

\section{Scale-dependent effects of forest area on plant-pollinator networks}

The species-area relationships were vastly different between plant and pollinator species when exotic species were included in the analyses (Figures 3a,c). Additionally, the spatial scale at which the highest correlation coefficient was found differed between plant and pollinator species (Figure 2a). Responses to habitat area are generally different between plant and pollinator species [19]. However, the scale-dependent relationship was similar among the number of plant species, pollinator species, and interaction links, when exotic species as well as native species only observed interacting with exotics were excluded (Figure 2b, 6b). The similarities among the relationships between native plant and pollinator species are not likely to have been caused by our sampling scheme (i.e., insect collection on plants), because the results using a different sampling method (pan traps) also showed that native bee abundance and diversity increased with increasing forest area (with the highest correlation coefficients at 500-750 m radius [46]). The study [46] was conducted in the same region, but in different study forests (where $A$. petiolata did not flower). Therefore, the similar responses of native plant and native pollinator species to forest area caused a positive relationship between forest area and the numbers of links at the same spatial scale (i.e., 820 m; Figures 6b, 7b).

Previous studies have indicated that network metrics, connectance and nestedness are related to the total number of species involved in mutualistic interactions [12-14,32,33]. Our results partly supported this pattern (Figures 5a,b,d; but Figure 5c,e,f). Although previous studies have used data sets composed of mutualistic networks at different sampling areas as well as different geographical regions [12-14,32,33], all of our data were collected from within the same sampling area $\left(234 \mathrm{~m}^{2}\right)$ in the same region. Because the total number of species was related to the forest area (Figures 3e,f), so was the 


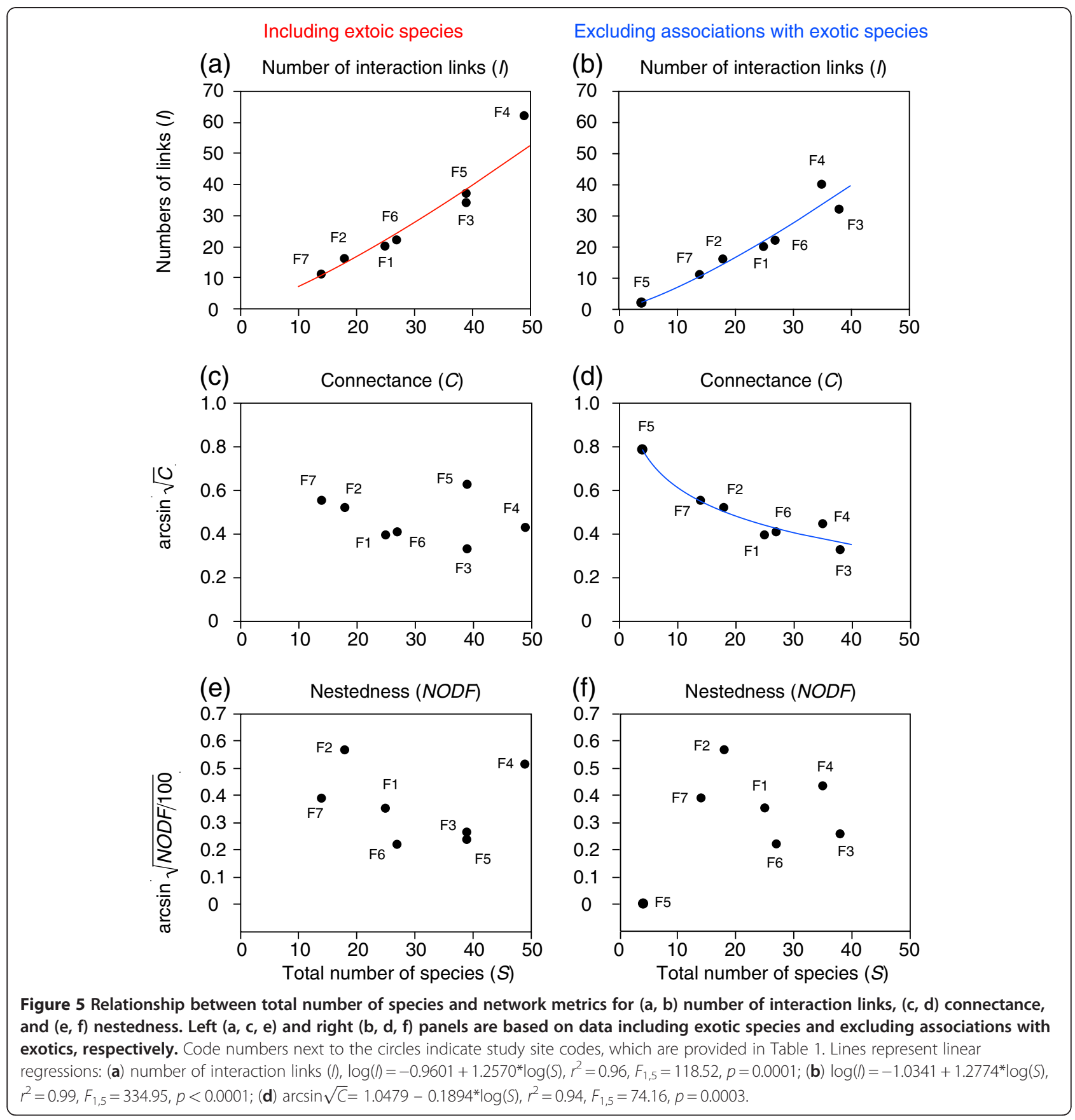

network structure (Figures 7a,b,d,e,f). More redundant networks with highly asymmetric interactions were found in relatively large forest areas (Figure $7 \mathrm{~d}, \mathrm{e}, \mathrm{f}$ ), suggesting that the stability of plant-pollinator networks might increase with forest area. However, these relationships may partly be explained by nonbiological factors. For example, connectance may decrease with increasing numbers of possible interaction links, as the number of observations per species declines when the same absolute effort is made to sample networks of different sizes [31,34].
In this study, however, connectance did not decrease with the total number of species when exotic species were included (Figure 5c). Also, nestedness was not related to the total number of species (Figures $5 \mathrm{e}, \mathrm{f}$ ), although it increased with increasing forest area (Figures $7 \mathrm{e}, \mathrm{f})$. These results suggest that the effects of forest area on connectance or nestedness were caused not only by changes in the total number of species, but also by other factors. For example, changes in the population densities of some species might affect the structure of interaction networks 


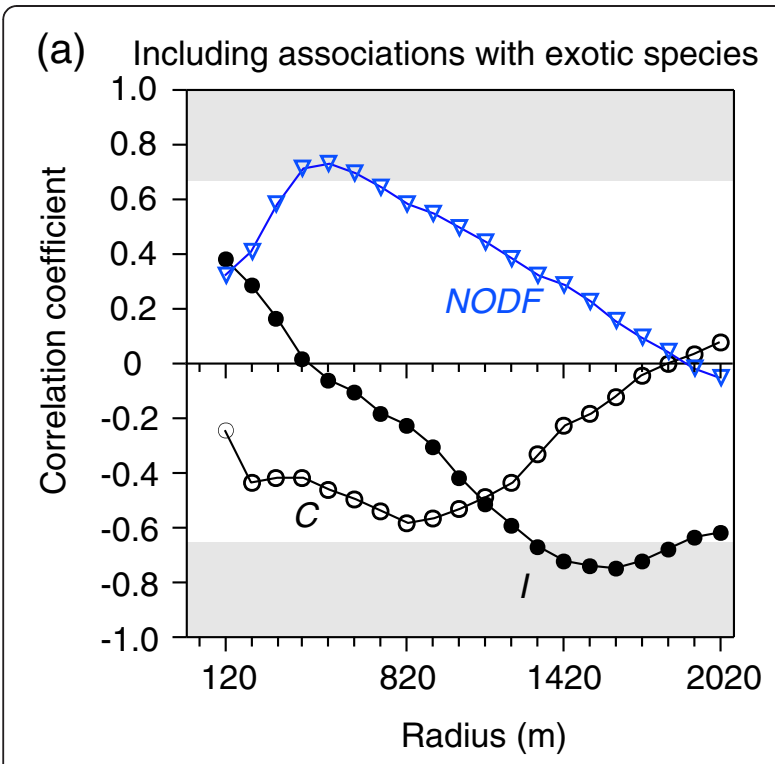

(b) Excluding associations with exotic species

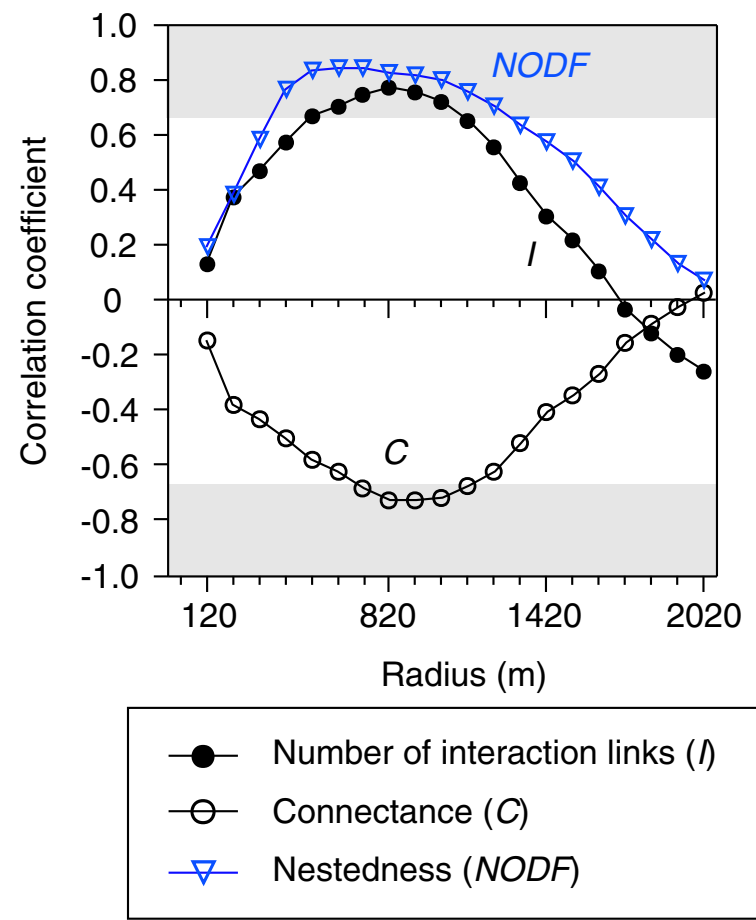

Figure 6 Correlation coefficients between forest area and network metrics (number of interaction links, connectance, and nestedness) at each radius (range: 120-2020 m) among the study forests: (a) including exotic species, (b) excluding associations with exotic species. Correlation coefficients in the shaded grey areas are statistically significant at $p=0.10$ level.

relative to habitat area because the population densities of various species are known to be related to habitat area [53]. Further studies are needed to clarify the mechanism driving the relationships between habitat area and network structure.

\section{Impacts of exotic species}

The scale-dependent relationships among forest area, total number of species, and interaction networks were different when interactions were considered with and without exotic species (Figures 2, 3, 5, 6, 7), suggesting impacts of exotic species. Plant-pollinator interactions included only two exotic species, garlic mustard A. petiolata and the honeybee A. mellifera (Additional file 2 and Additional file 3). Although the contribution of A. mellifera to the interactions was not insignificant (Additional file 3), A. petiolata was central to the interactions in at least two forests (Additional file 2). Although exotic plants are only rarely thought to invade temperate natural forests [24,54], A. petiolata has frequently been reported to invade the forest edge and understory in North America [38]. Flowers of $A$. petiolata produce rich nectar, attracting a variety of native bees and flies [55]. Nectarrich flowers of invasive plants can disturb native plantpollinator interactions [56]. In the study areas of the present study, A. petiolata, which has invaded relatively small forest patches surrounded by agricultural fields (Figure 4b), may have supported more native pollinator species than initially expected (Additional file 3).

The presence of exotic species strongly influenced the scale-dependent relationships between forest area and the number of interaction links and connectance (Figures $7 \mathrm{a}-\mathrm{d}$ ). Thus, this invasive plant may have altered the original relationships between forest area and plant-pollinator networks and their scale-dependency. However, nestedness showed the same trend for both networks, with and without exotics (Figures 7e,f). Vilá et al. [23] hypothesised that invasive plants by being supergeneralists, both interacting with generalists and specialists, would increase the nestedness of the plantpollinator network. Our results showed that excluding associations with exotic species increased the values of nestedness in some study sites (Figures 7e,f). However, this increase did not change the relationships between forest area and nestedness (Figures 7e,f).

\section{Conclusions}

Since the original publication of the equilibrium theory of island biogeography [1], species-area relationships have been extensively studied for various groups of organisms $[3,4]$. Furthermore, the theory has been applied to the conservation of focal species in continental habitats $[4,5]$. Sugiura [9] analysed the relationships between island area and plant-ant mutualistic interactions and suggested an extension of this basic species-area relationship to more specifically address "species interactions-area relationships". Interaction networks on continental habitats as well as oceanic islands can be considered with a view to the species interactions-area relationships. Indeed, Sabatino et al. [11] indicated that the number of 


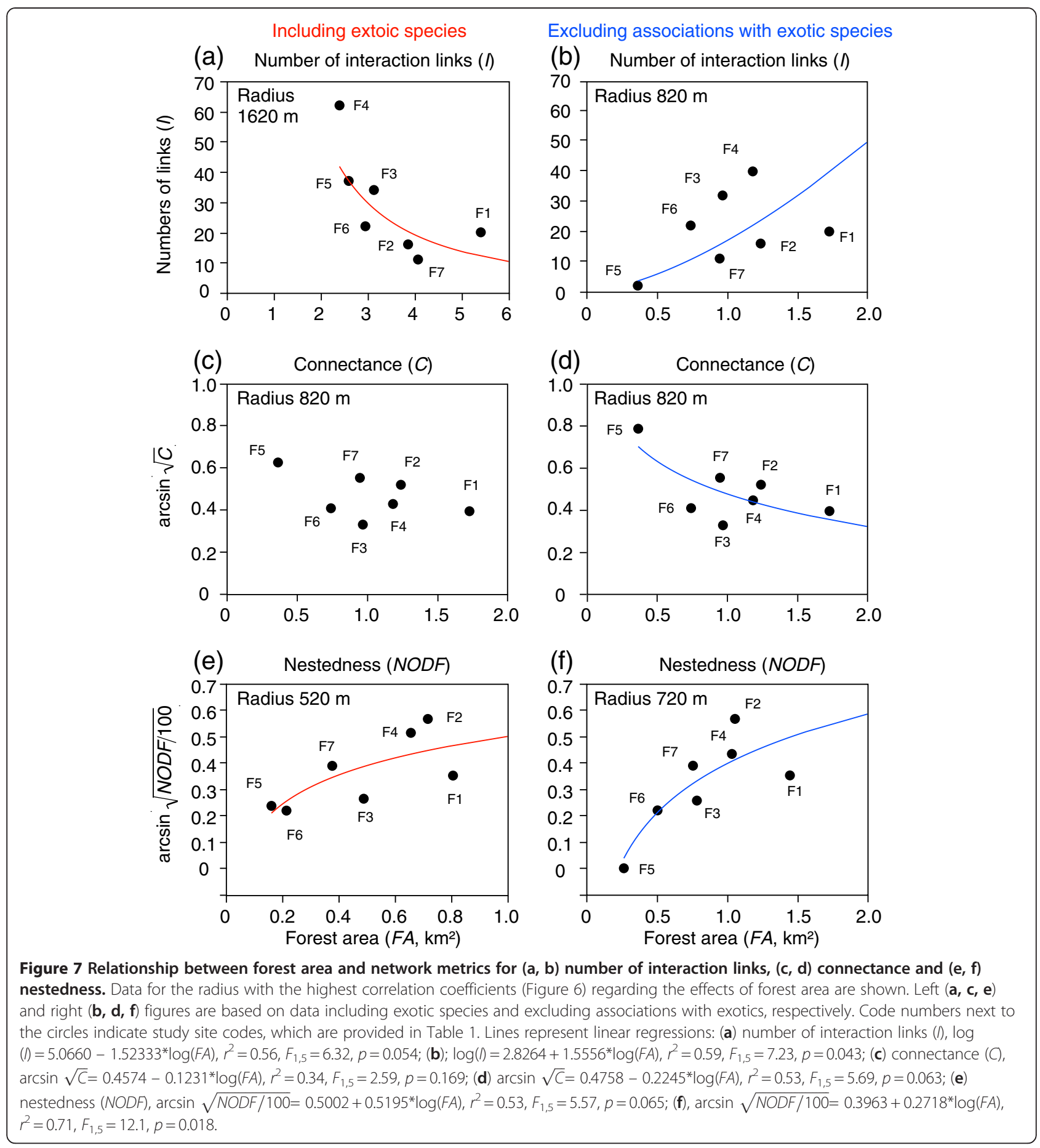

interaction links among flowering plants and their pollinators increases with habitat area in the continental environment. Valladares et al. [15] also indicated that the network structure of plant-leafminer-parasitoid webs is related to fragmented forest area. In this study, we determined that network metrics of plant-pollinator interactions are related to forest area and the relationships depend on spatial scale.
Each species has a particular spatial scale of habitat area that most strongly affects the abundance because body size and mobility differ among species [19,44]. Therefore, the spatial scales of habitat area that most strongly affected the abundance generally differed among species [19]. In this study, we determined the spatial scales that most strongly affected the structure of plant-pollinator interactions, which suggests the 
presence of a spatial scale that most strongly influences the structuring and maintenance of the species interaction network.

Finally, exotic species appear to alter the relationship between habitat area and interaction network. Although many researchers have reported that exotic species impact interaction networks, particularly on oceanic islands [9,14,57-59], we suggest that a single exotic plant species can impact this relationship, even in temperate continental habitats.

\section{Additional files}

Additional file 1: Seven study sites with 20 radii ranging from $120 \mathrm{~m}$ to $2020 \mathrm{~m}$ (100-2000 $\mathrm{m}$ from the hexagonal transects) used to obtain forest area. All sites were in Norfolk Country, Ontario, Canada. Shaded areas represent forests, and the bar indicates a $2000 \mathrm{~m}$ scale. The geospatial data were obtained from the Ontario Base Map Series in 2003 (Ontario Ministry of Natural Resources, Peterborough, Ontario, Canada), Code numbers indicate study site codes, which are provided in Table 1.

\section{Additional file 2: List of plant species at each forest site.}

Additional file 3: List of pollinator species at each forest site.

Additional file 4: Hexagonal transect with $20 \mathrm{~m}$ sides, with the chosen geographical point marking the centre (top). The axes were marked with bamboo poles and a $120 \mathrm{~m}$ section of rope demarcated the perimeter (bottom).

\section{Competing interests}

The authors declare that they have no competing interests.

\section{Authors' contributions}

SS and HT generated the original idea. HT designed the research. HT collected field data. SS and HT analysed data. SS wrote the paper. All authors read and approved the final manuscript.

\section{Acknowledgements}

We thank Long Point Conservation Authority personnel, M. Armstrong, J. DeCloet, J. Knack, F. Saul and V. Sinnave for allowing us to access our study sites. We also thank P. Kevan, C. Fuss and A. and J. Boone for support and field assistance. We thank $O$. Honnay and anonymous reviewers for helpful comments on an earlier version of the manuscript. While conducting the field work, HT was supported by a scholarship from the Rotary Foundation. Financial support was provided by the Forestry and Forest Products Research Institute.

Received: 10 February 2012 Accepted: 3 July 2012

Published: 20 July 2012

\section{References}

1. MacArthur RH, Wilson EO: The theory of island biogeography. Princeton: Princeton University Press; 1967

2. Connor EF, McCoy ED: The statistics and biology of the species-area relationship. American Naturalist 1979, 5:397-411.

3. Rosenzweig ML: Species diversity in space and time. Cambridge: The University of Cambridge; 1995.

4. Lomolino MV: Ecology's most general, yet protean pattern: the speciesarea relationship. Journal of Biogeography 2000, 27:17-26.

5. Diamond JM: The island dilemma: lessons of modern biogeographic studies for the design of natural reserves. Biological Conservation 1975 7:129-146.

6. Quammen D: The song of the dodo: Island biogeography in an age of extinctions. New York, London, Toront, Sydney: Scribner; 1996.

7. Laurance WF: Beyond island biogeography theory: understanding habitat fragmentation in the real world. Princeton University Press: In The theory of island biogeography revisited. Edited by Losos JB, Ricklefs RE. Princeton, NJ; 2010:214-236.

8. He F, Hubbell SP: Species-area relationships always overestimate extinction rates from habitat loss. Nature 2011, 478:368-371.

9. Sugiura S: Species interactions-area relationships: biological invasions and network structure in relation to island area. Proceedings of the Royal Society B 2010, 277:1807-1815.

10. Burkle LA, Alarcón R: The future of plant-pollinator diversity: understanding interaction networks across time, space, and global change. American Journal of Botany 2011, 98:528-538.

11. Sabatino M, Maceira N, Aizen MA: Direct effects of habitat area on interaction diversity in pollination webs. Ecological Applications 2010, 20:1491-1497.

12. Jordano P: Patterns of mutualistic interactions in pollination and seed dispersal: connectance, dependence asymmetrics, and coevolution. American Naturalist 1987, 129:657-677.

13. Guimarães PRJ, Rico-Gray V, dos Reis SF, Thompson JN: Asymmetries in specialization in ant-plant mutualistic networks. Proceedings of the Royal Society B 2006, 273:2041-2047.

14. Aizen MA, Morales CL, Morales JM: Invasive mutualists erode native pollination webs. PLoS Biology 2008, 6:e31

15. Valladares G, Cagnolo L, Salvo A: Forest fragmentation leads to food web contraction. Oikos 2012, 121:299-305.

16. Losos JB, Schluter D: Analysis of an evolutionary species-area relationship. Nature 2000, 408:847-850.

17. Crawley MJ, Harral JE: Scale dependence in plant biodiversity. Science 2001, 291:864-868.

18. Hubbell SP: The unified neutral theory of biodiversity and biogeography. Princeton: Princeton University Press; 2001

19. Steffan-Dewenter I, Tscharntke T: Insect communities and biotic interactions on fragmented calcareous grasslands-a mini review. Biological Conservation 2002, 104:275-284.

20. Montoya JM, Pimm SL, Sole RV: Ecological networks and their fragility Nature 2006, 442:259-264.

21. Ings TC, Montoya JM, Bascompte J, Blüthgen N, Brown L, Dormann CF, Edwards F, Figueroa D, Jacob U, Jones JI, Lauridsen RB, Ledger ME, Lewis HM, Olesen JM, van Veen FJ, Warren PH, Woodward G: Ecological networks beyond food webs. Journal of Animal Ecology 2008, 78:253-69.

22. Memmott J, Waser NM: Integration of alien plants into a native flowerpollinator visitation web. Proceedings of the Royal Society of London B 2002, 269:2395-2399.

23. Vilà M, Bartomeus I, Dietzsch AC, Petanidou T, Steffan-Dewenter I, Stout JC, Tscheulinm T: Invasive plant integration into native plant-pollinator networks across Europe. Proceedings of the Royal Society B 2009, 276:3887-3893.

24. Elton CS: The ecology of invasions by animals and plants. London: Methuen 1958.

25. Simberloff D: Why do introduced species appear to devastate islands more than mainland areas? Pacific Science 1995, 49:87-97.

26. Corlett RT: Invasive aliens on tropical East Asian islands. Biodiversity and Conservation 2010, 19:411-423.

27. Lewinsohn TM, Prado Pl, Jordano P, Bascompte J, Olesen JM: Structure in plant-animal interaction assemblages. Oikos 2006, 113:174-184.

28. Bascompte J, Jordano P: Plant-animal mutualistic networks: the architecture of biodiversity. Annual Review of Ecology, Evolution, and Systematics 2007, 38:567-593.

29. Vázquez DP, Blüthgen N, Cagnolo L, Chacoff NP: Uniting pattern and process in plant-animal mutualistic networks: a review. Annals of Botany 2009, 103:1445-1457.

30. Bascompte J, Jordano P, Melián CJ, Olesen JM: The nested assembly of plant-animal mutualistic networks. Proceeding of the National Academy of Sciences USA 2003, 100:9383-9387.

31. Blüthgen N, Fründ J, Vázquez DP, Menzel F: What do interaction network metrics tell us about specialization and biological traits? Ecology 2008 89:3387-3399.

32. Olesen JM, Jordano P: Geographic patterns in plant-pollinator mutualistic networks. Ecology 2002, 83:2416-2424.

33. Blüthgen N, Menzel F, Hovestadt T, Fiala B, Blüthgen N: Specialization, constraints, and conflicting interests in mutualistic networks. Current Biology 2007, 17:341-346

34. Kenny D, Loehle C: Are food webs randomly connected? Ecology 1991, 72:1794-1799. 
35. Taki H, Kevan PG: Does habitat loss affect the communities of plants and insects equally in plant-pollinator interactions? Preliminary findings. Biodiversity and Conservation 2007, 16:3147-3161

36. Waldron G: Trees of the Carolinian forest: a guide to species, their ecology and uses. Toronto: Boston Mills Press; 2003.

37. Traveset A, Richardson DM: Biological invasions as disruptors of plant reproductive mutualisms. Trends in Ecology and Evolution 2006, 21:208-216.

38. Stinson K, Kaufman S, Durbin L, Lowenstein F: Impacts of Garlic Mustard invasion on a forest understory community. Northeastern Naturalist 2007, 14:73-88.

39. Memmott J: The structure of a plant-pollinator food web. Ecology Letters 1999, 2:276-280

40. Macior LW: Pollination ecology of vernal angiosperms. Oikos 1978, 30:452-460.

41. Schemske DW, Wilson MF, Melampy MN, Miller LJ, Verner L, Schemske KM, Best LB: Flowering ecology of some spring woodland herbs. Ecology 1978, 59:351-366.

42. Helenurm K, Barrett SCH: The reproductive biology of boreal forest herbs. II. Phenology of flowering and fruiting. Canadian Journal of Botany 1987, 65:2047-2056.

43. Osborne JL, Clark SJ, Morris JR, Williams $\|_{H}$, Riley JR, Smith AD, Reynolds DR, Edwards AS: A landscape-scale study of bumble bee foraging range and constancy, using harmonic radar. Journal of Applied Ecology 1999, 36:519-533.

44. Steffan-Dewenter I, Münzenberg U, Bürger C, Thies C, Tscharntke T: Scaledependent effects of landscape context on three pollinator guilds. Ecology 2002, 83:1421-1432.

45. Gathmann A, Tscharntke T: Foraging ranges of solitary bees. Journal of Animal Ecology 2002, 71:757-764.

46. Taki H, Kevan PG, Ascher JS: Landscape effects of forest loss in a pollination system. Landscape Ecology 2007, 22:1575-1587.

47. Fahrig L: Effects of habitat fragmentation on biodiversity. Annual Review of Ecology, Evolution and Systematics 2003, 34:487-515.

48. May RM: Stability and complexity in model ecosystems. Princeton, NJ: Princeton University Press; 1973

49. Ulrich W, Almeida-Neto M, Gotelli NJ: A consumer's guide to nestedness analysis. Oikos 2009, 118:3-17.

50. Atmar W, Patterson BD: The measure of order and disorder in the distribution of species in fragmented habitat. Oecologia 1993, 96:373-382

51. Guimarães PRJ, Guimarães P: Improving the analyses of nestedness for large sets of matrices. Environmental Modeling and Software 2006, 21:1512-1513.

52. Almeida-Neto M, Guimarães PR, Guimarães PRJ, Loyola RD, Ulrich W: A consistent metric for nestedness analysis in ecological systems: reconciling concept and measurement. Oikos 2008, 117:1227-1239.

53. Connor EF, Courtney AC, Yoder JM: Individual-area relationships: the relationship between animal population density and area. Ecology 2000, 81:734-748.

54. Von Holle B, Delcourt HR, Simberloff D: The importance of biological inertia in plant community resistance to invasion. Journal of Vegetation science 2003, 14:425-432

55. Cruden RW, McClain AM, Shrivastava GP: Pollination biology and breeding system of Alliaria petiolata (Brassicaceae). Bulletin of the Torrey Botanical Club 1996, 123:273-280.

56. Lopezaraiza-Mikel ME, Hayes RB, Whalley MR, Memmott J: The impact of an alien plant on a native plant-pollinator network: an experimental approach. Ecology Letters 2007, 10:539-550.

57. Olesen JM, Eskildsen LI, Venkatasamy S: Invasion of pollination networks on oceanic islands: importance of invader complexes and endemic super generalists. Diversity and Distributions 2002, 8:181-192.

58. Sugiura S, Yamaura Y, Makihara H: Biological invasion into the nested assemblage of tree-beetle associations on the oceanic Ogasawara Islands. Biological Invasions 2008, 10:1061-1071.

59. Padrón B, Traveset A, Biedenweg T, Díaz D, Nogales M, Olesen JM: Impact of alien plant invaders on pollination networks in two archipelagos. PLOS ONE 2009, 4:e6275.

doi:10.1186/1472-6785-12-11

Cite this article as: Sugiura and Taki: Scale-dependent effects of habitat area on species interaction networks: invasive species alter relationships. BMC Ecology 2012 12:11.

\section{Submit your next manuscript to BioMed Central and take full advantage of:}

- Convenient online submission

- Thorough peer review

- No space constraints or color figure charges

- Immediate publication on acceptance

- Inclusion in PubMed, CAS, Scopus and Google Scholar

- Research which is freely available for redistribution 